\title{
A gestão do Ensino Fundamental pelo governo do estado de São Paulo: Uma análise do financiamento e dos indicadores sociais de educação (1980-1993)*
}

Paulo Sérgio Fracalanza **

RESUMO: Este artigo contribui para a avaliação do Sistema Educacional de Ensino Fundamental gerido pelo governo do estado de São Paulo, por intermédio de sua Secretaria de Educação, no período de 1980 a 1993. Para tanto, foi realizado um estudo empírico do financiamento da educação no estado e agregadas informações de alguns indicadores sociais de educação.Mostra-se que, ao longo do período de análise, o volume de recursos alocado neste nível de ensino não evoluiu positivamente, embora tenha se ampliado significativamente o número de matrículas, bem como, proporcionalmente, a rede física e os recursos humanos. Uma das decorrências desse processo foi a brutal perda do poder aquisitivo do salário dos professores. Além disso, entre outros aspectos, evidencia-se a baixa eficiência do sis-

* Este texto foi escrito com base na dissertação de mestrado em Economia do autor, apresentada à Faculdade de Economia, Administração e Ciências Contábeis (FEA) da USP, sob orientação da professora-doutora Basília Maria Baptista Aguirre. Esta pesquisa contou com apoio da Fapesp.

** Bacharel em Ciências Econômicas e Ciências Sociais pela Unicamp e mestre em Economia pela FEA/USP. Realizou doutorado-sanduíche na Universidade Louis Pasteur, em Estrasburgo, França. Atualmente é doutorando no Instituto de Economia da Unicamp, com concentração em Economia do Trabalho, e professor das disciplinas de matemática para economistas na graduação do curso de Economia da Unicamp. Email: fracalan@eco.unicamp.br 
tema de ensino, com elevadas taxas de repetência, práticas pedagógicas autoritárias, professores desmotivados e deficientes instalações dos estabelecimentos de ensino.

Palavras-Chave: Financiamento, ensino público fundamental, indicadores sociais de educação, estado de São Paulo, eficiência do sistema de ensino.

\section{Introdução}

Este artigo contribui para a avaliação do sistema educacional de ensino fundamental gerido pelo governo do estado de São Paulo por intermédio de sua Secretaria da Educação, no período de 1980 a 1993. Para tanto, foi realizado um estudo empírico do financiamento da educação nesse estado e agregadas informações de alguns indicadores sociais de educação.

Em uma primeira parte, discute-se o importante papel que a educação pode desempenhar no desenvolvimento brasileiro. Por um lado, por entender que a formação dos recursos humanos é um dos determinantes de maior importância para o aumento da competitividade, sobretudo no cenário das mudanças imprimidas pela Terceira Revolução Industrial. Por outro lado, pela contribuição que a educação pode desempenhar na diminuição das extensas desigualdades sociais do país.

Em uma segunda parte, na qual se trata das questões do financiamento da educação e da evolução dos indicadores sociais de educação, mostra-se que ao longo do período de análise o volume de recursos alocado no nível de Ensino Fundamental pela Secretaria da Educação do estado de São Paulo pouco se modificou, embora tenha se ampliado significativamente o número de matrículas, bem como, proporcionalmente, a rede física e o número de docentes.

Em decorrência desse processo, foi brutal a diminuição do poder aquisitivo dos salários dos professores da rede pública estadual paulista de Ensino Fundamental. Além disso, a análise dos indicadores sociais de educação evidencia a baixa eficiência desse sistema de ensino que apresenta elevadas taxas de repetência, professores 
desmotivados e instalações deficientes dos estabelecimentos de ensino.

\section{Educação e desenvolvimento}

A educação ocupa atualmente lugar de destaque nos trabalhos acadêmicos, programas políticos, documentos empresariais e na mídia impressa e eletrônica. Embora tal fato mereça ser louvado e a oportunidade política, aberta pelos debates, não deva ser desperdiçada, muitos dos discursos tendem a atribuir à educação virtudes muito maiores do que as que ela pode corresponder.

A idéia de que a educação representa elemento de fundamental importância para viabilizar o crescimento econômico parece ser largamente consensual. Porém, a concepção, também bastante difundida, de que a ampliação das oportunidades de ensino se constitui em veículo seguro para a diminuição das desigualdades sociais parece não resistir à comprovação histórica.

O exemplo brasileiro pode ser destacado como contraprova desta última formulação. Com efeito, desde o segundo pós-guerra até meados dos anos 70, o Brasil viveu um período de acelerado crescimento econômico. Ao longo desses anos, e particularmente a partir da década de 1970, o sistema educacional brasileiro foi profundamente revolucionado. Houve uma brutal expansão do número de matrículas e da infra-estrutura física e humana em todos os níveis de ensino. Ignorando por ora a qualidade efetiva do ensino praticado, pode-se afirmar com segurança ter havido uma democratização bastante significativa no que diz respeito ao acesso ao ensino, estendido para grande parte da população em idade escolar. Contudo, para esse mesmo período, os indicadores de pobreza e de concentração de renda comprovam de maneira inequívoca o agravamento do já perverso quadro brasileiro de heterogeneidade social.

A educação, por si só, não pode servir para a diminuição das desigualdades sociais, pois a simples garantia de uma melhor distribuição das oportunidades de crescimento individual resultaria insuficiente na ausência de transformações em outros campos da vida social. Na perspectiva deste trabalho, alguns argumentos vêm reforçar essa proposição.

Assim, entende-se que apenas investir em recursos humanos não significa garantir a incorporação da mão-de-obra mais qualifica- 
da em funções compatíveis com seu potencial. ${ }^{1}$ Ao contrário, poderia suceder a criação de um expressivo contingente de trabalhadores com elevados níveis de qualificação exercendo ocupações secundárias e caracterizadas pela precariedade das relações de trabalho, tal qual se verifica hoje em grande parte das nações desenvolvidas. Ademais, afirma-se que pela via do mercado não são criadas as condições para o enfrentamento dos problemas das desigualdades sociais. Estes são, em grande medida, condicionados por diferenças de riqueza e poder entre os diversos grupos sociais, diferenças aliás que, potencialmente, interferem não apenas no aproveitamento escolar dos estudantes, como também quando, egressos dos bancos escolares, estes devem enfrentar o mercado de trabalho.

Descartando o enfoque meramente técnico que vincula à função educacional a produção de trabalhadores com determinadas habilitações demandadas pelo mercado de trabalho, deve-se adotar uma perspectiva em que sejam destacadas as formas de consciência, personalidade e sociabilidade estimuladas e reforçadas pela educação. Resgata-se, dessa maneira, a dimensão política do processo educacional, que pode ter um papel importante na capacitação dos cidadãos para a discussão dos valores e das atitudes que devem ser reforçados para a convivência em sociedades plurais e democráticas. Além do mais, a escola pode também servir para a revalorização de determinados conteúdos éticos e para a criação de movimentos políticos orientados no sentido do fortalecimento de uma consciência social para os problemas das desigualdades sociais. $^{2}$

De outra parte, deve-se considerar o impacto que as novas tecnologias trazidas na esteira da Terceira Revolução Industrial exercem sobre o mundo do trabalho. As empresas comprometidas com os processos de reestruturação industrial exigem trabalhadores com níveis de qualificação mais elevados, sendo destacadas as qualidades que resultam de uma sólida educação geral, tais como raciocínio abstrato, habilidade para alternar tarefas, contornar possíveis problemas no processo produtivo e oferecer soluções para sua resolução, além de requisitos de sociabilidade e de cooperação. ${ }^{3}$

É útil notar que os prejuízos de uma insuficiente formação escolar não se circunscrevem apenas ao campo laboral. Novas formas de exclusão são criadas, a exemplo do que ocorre com a difusão cada vez em maior escala dos produtos das novas tecnologias de informação, onde os indivíduos que não dominam os códigos de linguagem escrita e 
numérica encontram dificuldade crescente na manipulação desses novos instrumentos.

É no âmbito da argumentação até aqui desenvolvida que se deve entender a importância da educação como um dos elementos destacados no sentido da redução das heterogeneidades sociais.

\section{O financiamento da educação}

Com base nesses pressupostos, a pergunta que se coloca é: qual a situação do ensino no país? Na impossibilidade de trabalhar empiricamente um universo de tal porte, recortou-se a atuação do governo do estado de São Paulo no nível de Ensino Fundamental, entre os anos de 1980 e 1993. Isso se justifica pela importância econômica desse estado, pela dimensão quantitativa de sua população em idade escolar, bem como pelo papel destacado da rede pública estadual no atendimento dos alunos desse nível de ensino. ${ }^{4}$

No tratamento dessa questão, o estudo do financiamento da educação é considerado fundamental, uma vez que se compreende que os dados quantitativos sobre o financiamento permitem que se acompanhem a evolução e a destinação dos recursos empenhados na educação. Além do mais, a análise de tais dados, articulada com a avaliação de alguns indicadores sociais de educação, possibilita concretizar algumas interpretações sobre a situação do Ensino Fundamental oferecido pela rede pública do estado de São Paulo em seus aspectos quantitativos e qualitativos.

É importante ressaltar que existe um particular interesse em estudar os anos 80 , marcados por acontecimentos que repercutiram amplamente no financiamento da educação para os estados brasileiros. Entre esses acontecimentos destacam-se: as eleições diretas para os governos de estado em 1982 que principiaram por desmontar a política educacional articulada pelo regime militar, ${ }^{5}$ a Emenda Calmon, em 1983, que consagrou um aumento dos percentuais mínimos da receita de impostos a serem aplicados nos gastos com educação e, finalmente, a Constituição Federal de 1988.

Para compreender a questão do financiamento da educação é necessário observar as disposições e alterações na legislação que 
disciplina os recursos destinados às despesas com a manutenção e o desenvolvimento do ensino.

Em 1983 é criada a Emenda nº 24/83, denominada de Emenda Calmon, que determinava os percentuais mínimos da receita de impostos a serem aplicados nos gastos com educação pela União, estados e municípios. Pelo teor da emenda, os estados e municípios deveriam aplicar nunca menos do que $25 \%$ e a União $13 \%$ de sua receita de impostos na manutenção e no desenvolvimento do ensino. ${ }^{6}$

Em 1988, com a promulgação da nova Constituição da República Federativa do Brasil, são introduzidas alterações no financiamento da educação para os estados brasileiros. É importante notar que, de acordo com o texto constitucional, ficam proibidas as vinculações de recursos a órgãos, fundos ou despesas. As únicas exceções são feitas aos Fundos de Participação dos estados e municípios e à aplicação de recursos para o desenvolvimento e a manutenção do ensino.

O artigo 212 da Constituição Federal disciplina que nunca menos do que $18 \%$ da receita de impostos da União e $25 \%$ da receita de impostos dos estados e municípios devem ser aplicados na manutenção e no desenvolvimento do ensino. Assim, os percentuais mínimos de vinculação para os estados e municípios não sofrem alteração em relação à Emenda Calmon, enquanto, para a União, a alíquota vinculada sobe de $13 \%$ para $18 \%$.

Outra importante modificação introduzida pelo texto constitucional foi a recuperação e a ampliação das prerrogativas fiscais dos estados e municípios brasileiros. Duas razões, aliás, têm sido apontadas para explicar o fortalecimento da posição financeira dos governos subnacionais, ambas relacionadas com as mudanças trazidas pela Constituição de 1988. Em primeiro lugar, os estados e municípios foram beneficiados com um aumento substancial de suas competências tributárias. Em segundo lugar, os governos subnacionais aumentaram sua participação na arrecadação de seus governos superiores. ${ }^{7}$

Os recursos da Secretaria da Educação do Estado de São Paulo

A Secretaria da Educação do Estado de São Paulo (Seesp) dispõe das seguintes fontes de financiamento para a educação: 
- Tesouro do Estado;

- Quota Estadual do Salário-Educação (QESE);

- transferências federais;

- recursos próprios;

- recursos vinculados aos Fundos Especiais de Despesa.

Os recursos do Tesouro do Estado são originados pela arrecadação tributária do estado e representam a parcela mais importante dos recursos da Secretaria da Educação. Controlados pela Secretaria da Fazenda do estado, os recursos do Tesouro destinados à educação são depositados numa conta do Banco do Estado de São Paulo (Banespa) que, por sua vez, efetua as transferências diretamente para as unidades de despesa. A maior parte desses recursos é utilizada em despesas correntes, principalmente no pagamento de pessoal.

Os recursos originados das outras fontes, com exceção dos recursos vinculados aos Fundos Especiais de Despesa, gastos nas próprias unidades geradoras, são depositados em uma conta do Banespa em nome do Fundo de Desenvolvimento da Educação do Estado de São Paulo (Fundesp).

Os recursos do Fundesp têm importância estratégica para o planejamento e a gestão das políticas educacionais formuladas pela Seesp pois, ao contrário dos recursos oriundos do Tesouro do Estado, são administrados pela própria Secretaria. A cada ano, a Secretaria da Educação, por meio de seus órgãos de planejamento, em conjunto com as unidades orçamentárias, elabora um Plano Anual de Trabalho definindo a alocação dos recursos previstos do Fundesp entre os diversos itens de despesa, excluindo-se as despesas com pessoal. Os principais itens de despesa efetuados pelo Fundesp são: serviços de terceiros e encargos, investimentos e transferências a municípios.

Sem dúvida, a fonte de recursos mais importante para o Fundesp é a Quota Estadual do Salário-Educação (QESE). Esta não pode financiar despesas com pessoal e sua aplicação destina-se exclusivamente para o financiamento do Ensino Fundamental, principalmente no custeio de obras escolares, despesas com material permanente e merenda escolar. 
O salário-educação foi criado pela Lei no 4.440 de 27/10/64. Após uma série de reformas, o Decreto 87.043 de 1982 descreve o salário-educação como

uma obrigação compulsória que visa suplementar os recursos públicos destinados à manutenção e ao desenvolvimento do ensino de primeiro grau, mediante a obrigação estabelecida para as empresas comerciais, industriais e agrícolas de manter o ensino de primeiro grau gratuito para seus empregados e para os filhos destes, entre os 7 e os 14 anos, ou a concorrer para esse fim. ${ }^{8}$

O salário-educação a ser pago pelas empresas é calculado por meio de uma alíquota de 2,5\% sobre a Folha de Salário-Contribuição (FSC). Dois terços do total dos recursos integram a Quota Estadual do Salário-Educação (QESE). A QESE é repassada aos estados de origem proporcionalmente à arrecadação realizada em cada estado. Uma segunda conta, referente ao outro um terço dos recursos, é enviada para o Fundo Nacional de Desenvolvimento da Educação (FNDE). Estes originam a Quota Federal do Salário-Educação (QFSE) que retorna aos estados em programas de iniciativa própria do MEC, voltados para a melhoria da eficiência escolar e a formação integral no Ensino Fundamental.

O repasse de recursos federais para o estado de São Paulo tem sido, historicamente, de pequena monta. Isso ocorre porque os recursos da União são distribuídos tendo como principal critério a diminuição das disparidades regionais. ${ }^{9}$

Os recursos próprios da Secretaria da Educação do Estado de São Paulo têm origem nos rendimentos de juros e correção monetária da aplicação de capitais ociosos do Fundesp no mercado financeiro. Quando da elaboração do orçamento pela Seesp supõe-se que os recursos do Fundesp não ficarão ociosos. Entretanto, a aplicação imediata dos recursos nem sempre é possível, ainda mais se for considerado que a Secretaria da Educação não tem perfeito controle sobre o volume e os prazos para os repasses de recursos efetuados pelo governo federal.

Por último, os recursos vinculados aos fundos especiais de despesa compreendem as taxas cobradas pelo departamento de recursos 
humanos e os recursos provenientes da comercialização da produção vegetal, animal e de derivados animais das escolas rurais. Tais recursos não transitam nem pelo Tesouro nem pelo Fundesp, sendo gastos nas próprias unidades geradoras. ${ }^{10}$

\section{A evolução das receitas e das despesas da Seesp}

O principal planejador e gestor das políticas educacionais para o Ensino Fundamental no estado de São Paulo é a Secretaria da Educação do Estado que gere a rede estadual de Ensino Fundamental e Médio, responsável por cerca de $80 \%$ do total das matrículas iniciais nesses níveis de ensino. ${ }^{11}$ Dentre os recursos orçamentários para o financiamento das despesas com a educação, o Tesouro do Estado representa, como se observou anteriormente, a fonte de recursos mais importante.

Para a análise das contas do estado e de seus órgãos de governo, o "Balanço Geral do Estado" constitui-se na publicação mais relevante. ${ }^{12}$ É importante notar que ao longo de um exercício fiscal, as receitas e as despesas realizadas pelo estado são somadas sem qualquer atualização monetária para a composição do Balanço. Assim, ao se deflacionarem os dados, adotou-se a hipótese de que os gastos realizados pela Secretaria da Educação do Estado de São Paulo distribuem-se uniformemente ao longo do ano. Essa hipótese é bastante plausível, pois parcela substancial das despesas dessa Secretaria é empenhada no pagamento de pessoal. Assim, os dados foram deflacionados a partir da taxa média de inflação anual medida pelo IGP$\mathrm{DI}$, tomando-se como base de referência os meses de julho e agosto de 1994, quando da implantação do Real. ${ }^{13}$

Como foi visto, a Constituição Federal de 1988 estabelece que os estados e municípios brasileiros devem empenhar, no mínimo, 25\% da arrecadação de impostos para o financiamento das despesas com a manutenção e o desenvolvimento do ensino. Uma vez que a maior parcela dos gastos efetuados pela Seesp advém da receita de impostos do estado, é fundamental perceber qual foi a evolução desse item das receitas ao longo do período estudado. ${ }^{14} \mathrm{O}$ gráfico I apresenta a evolução da receita total, das despesas totais, dos impostos e dos déficits do estado em termos reais para os anos compreendidos entre 1980 e 1993. 


\title{
Gráfico1
}

\begin{abstract}
DESPESAS TOTAIS, RECEITAS TOTAIS, IMPOSTOS E DÉFICITS DO GOVERNO DO ESTADO DE SÃO PAULO EM MILHÕES DE REAIS: 1980 - 1993
\end{abstract}

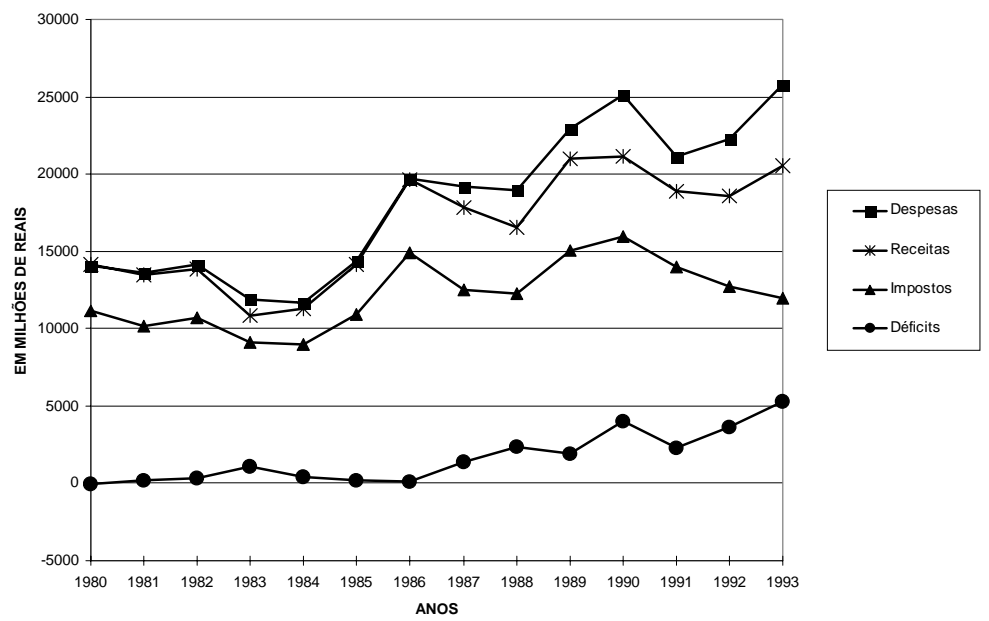

Fonte: Balanços Orçamentários do Estado de São Paulo (1980-1993).

Valores expressos em reais de julho/agosto de 1994, a partir da taxa média de inflação medida pelo IGP-DI.

Em primeiro lugar, avalia-se o comportamento dos impostos do estado de São Paulo. Como se pode verificar, as receitas de impostos apresentaram amplas oscilações ao longo do período de análise. Alguns fatores poderiam ter contribuído para tais oscilações. Entre eles, o nível de atividade econômica exerce, teoricamente, importante influência sobre a arrecadação tributária.

Dessa forma, nos anos da recessão de 1980-83 verifica-se a contração das receitas de impostos do governo do estado de São Paulo. O ano de 1984 marca o início de uma fase de recuperação da atividade econômica que atinge seu ápice em 1986, ano da implantação do Plano Cruzado, sendo que as receitas de impostos acompanham essa trajetória. Entre 1987 e 1988, refletindo a nova conjuntura recessiva, as receitas de impostos voltam a apresentar taxas de crescimento negativas. O paralelismo entre a evolução das receitas e o ritmo de atividade econômica persiste na breve fase de recuperação 
em 1989, que dará lugar a um novo período recessivo que marca os anos seguintes dos governos de Fernando Collor e Itamar Franco.

Além do mais, a partir de 1988, pode-se supor que parte do desempenho das receitas de impostos deveu-se à nova Constituição Federal que ampliou as prerrogativas fiscais dos estados brasileiros.

No gráfico I é também possível verificar visualmente a importância relativa das receitas de impostos no financiamento das despesas totais do governo do estado de São Paulo. Assim, enquanto em 1980 as receitas de impostos financiavam $79,4 \%$ do total das despesas do estado, em 1993 estas financiavam 46,4\% do total das despesas.

Interpretou-se que tal resultado seria em parte derivado da conjuntura recessiva que dominou a maior parte desse período. De outra parte, reconhece-se que, apesar do fraco desempenho das receitas tributárias estaduais, o governo não realizou qualquer esforço no sentido de se ajustar à nova realidade procurando reduzir seus gastos. Ao contrário, ao longo do período de análise observa-se um crescimento vigoroso das despesas estaduais, sendo que, particularmente após 1986, o estado passa a incorrer em déficits crescentes para fazer frente aos gastos ampliados. ${ }^{15}$

Mas não são apenas os déficits governamentais que se elevam continuamente. Verificou-se, a partir de 1988, um aumento significativo das receitas de capital. Dentro dessas receitas, sobretudo de 1989 em diante, as operações de crédito, que envolvem a captação de recursos por meio da contratação de dívidas, seguem uma trajetória de franca expansão.

O gráfico II apresenta o comportamento das despesas realizadas pela Secretaria da Educação do Estado de São Paulo, em termos reais, no período compreendido entre os anos de 1980 e 1993.

É possível notar que as despesas da Seesp, apesar das oscilações que se verificam, parecem não ter crescido de forma significativa. Com efeito, 13 anos passados do início do período de análise, as despesas efetuadas pela Seesp eram da mesma ordem de grandeza daquelas comprometidas em 1980. Para efeito de ilustração, pode-se dividir o período de análise em dois subperíodos. Assim, de 1980 a 1986, a média das despesas ficou em 2,24 bilhões de reais, montante pouco inferior ao da média do período 1986-1993 que ficou em 2,49 bilhões de reais. 


\section{Gráfico II}

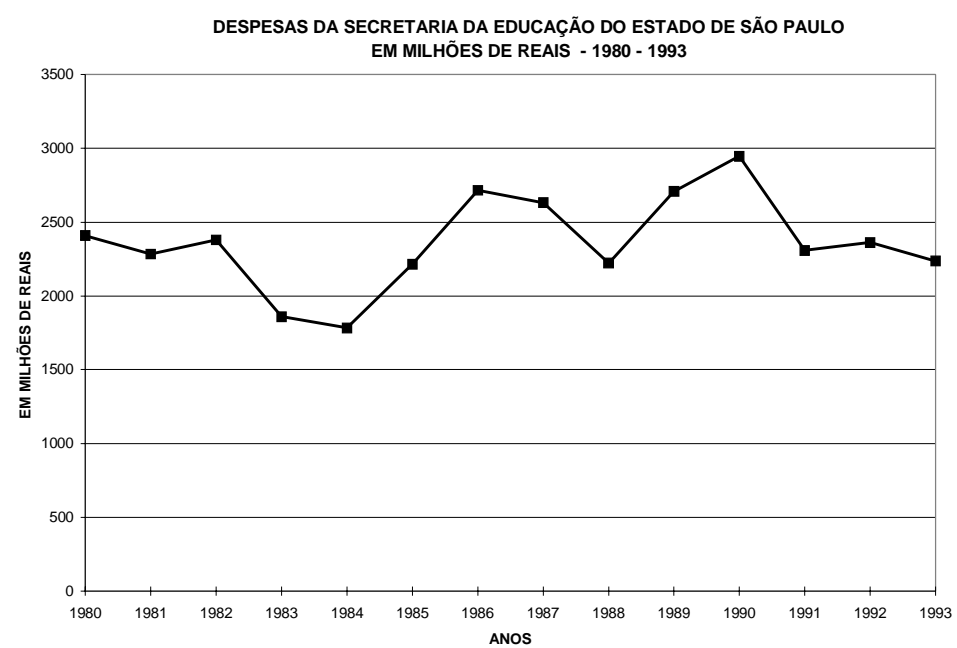

Fonte: Balanços Orçamentários do Estado de São Paulo (1980-1993).

Valores expressos em reais de julho/agosto de 1994, a partir da taxa média de inflação medida pelo IGP-DI.

As oscilações que se observam podem, em grande medida, ser explicadas pelas alterações no ritmo de atividade econômica e seus efeitos sobre a arrecadação tributária. É possível notar um grande paralelismo na trajetória dos gastos efetuados pela Seesp e as receitas de impostos do estado.

Uma vez que a participação das receitas de impostos no financiamento das despesas totais do estado decresceu ao longo do período estudado, houve uma retração substantiva das despesas realizadas pela Seesp como porcentagem das despesas totais efetuadas pelo governo do estado de São Paulo, o que se observa claramente no gráfico III. A evolução das despesas é bastante significativa: se no primeiro triênio da década de 1980 as despesas realizadas pela Secretaria da Educação representavam pouco menos de $17 \%$ das despesas totais do estado, nos três primeiros anos da década de 1990 respondiam por pouco mais de $10 \%$. 


\section{Gáfico III}

DESPESAS REALZADAS PELA SEESP COMO PORCENTAGEM DAS DESPESAS TOTAIS REALIZADAS PELO GOVERNO DO ESTADO DE SÃO PAULO - 1980 - 1993

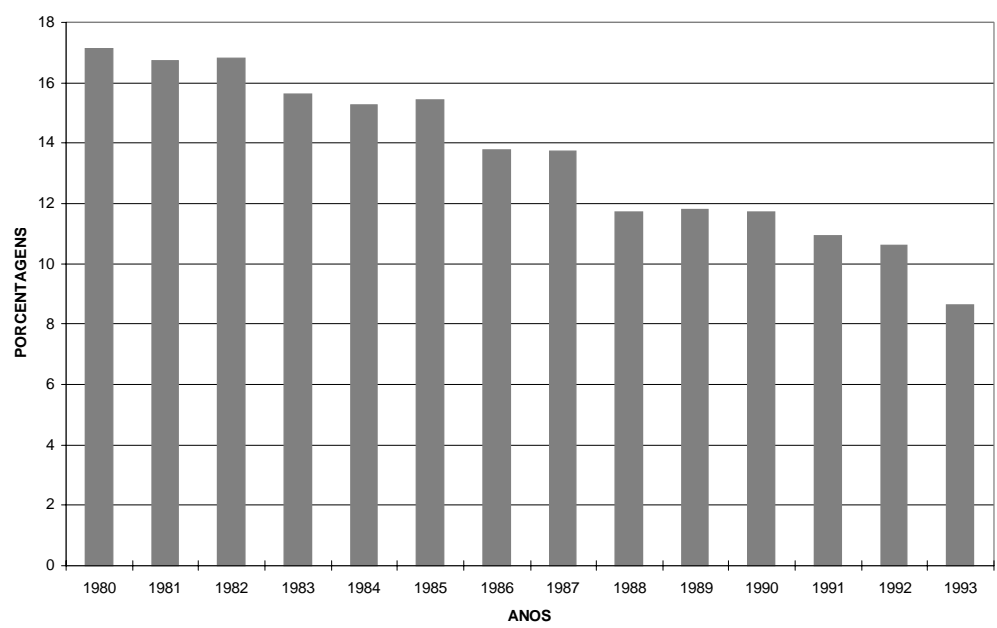

Fonte: Balanços Orçamentários do Estado de São Paulo (1980-1993).

Valores expressos em reais de julho/agosto de 1994, a partir da taxa média de inflação medida pelo IGP-DI.

O próximo ponto a ser tratado envolve a análise das despesas realizadas, discriminadas por categorias econômicas, e da contribuição de cada fonte de recurso para o financiamento dos gastos da Secretaria da Educação do Estado de São Paulo.

Dentro das despesas efetuadas pela Seesp deve-se destacar que o agregado pessoal e reflexos, que representa o somatório dos gastos com pessoal mais as despesas com transferência a famílias, representou em média $77 \%$ das despesas totais da Secretaria da Educação. Esses gastos são inteiramente financiados com recursos do Tesouro do Estado.

Para o financiamento de todas as outras despesas da Seesp, denominadas de outras despesas correntes e de capital, concorrem os recursos da Quota Estadual do Salário-Educação (QESE), recursos próprios e recursos do Tesouro do Estado. Os principais itens de despesa den- 
tro da categoria das outras despesas correntes e de capital são os investimentos, serviços de terceiros e encargos e transferências a municípios.

O gráfico IV apresenta o comportamento, em termos reais, das principais fontes de recursos da Seesp para o financiamento das outras despesas correntes e de capital.

\section{Gráfico IV}

FONTES DE RECURSOS PARA O FINANCIAMENTO DAS OUTRAS DESPESAS CORRENTES E DE CAPITAL DA SEESP EM MILHÕES DE REAIS - 1980 - 1993

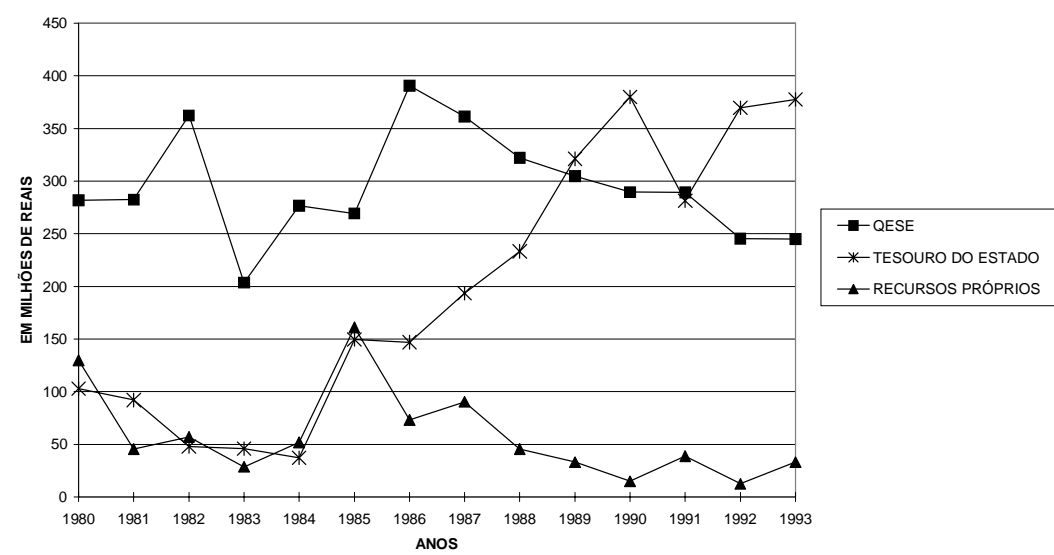

Fonte: Balanços Orçamentários do Estado de São Paulo (1980-1993).

Valores expressos em reais de julho/agosto de 1994, a partir da taxa média de inflação medida pelo IGP-DI.

A QESE tem importância estratégica para a Secretaria da Educação do Estado de São Paulo já que seus recursos são por lei destinados ao financiamento de despesas que não as de pessoal, além do que a gestão dos recursos fica a cargo da própria Secretaria. Entretanto, entre 1980 e 1993, se bem que com oscilações expressivas, o volume desses recursos não evoluiu positivamente. Para que se tenha uma idéia do que isso significa, pode-se dividir o período de análise em dois subperíodos. Assim, de 1980 a 1986 a média dos recursos da QESE era de 295,2 milhões de reais, superior à média desses recursos no período de 1987 a 1993, situada em 293,9 milhões de reais. 
Dessa forma, como é possível observar no gráfico IV, uma parcela maior das outras despesas correntes e de capital da Seesp passou a ser financiada pelo Tesouro do Estado. Em 1989, pela primeira vez os recursos originados do Tesouro do Estado tornaram-se mais importantes do que a QESE para o financiamento dos gastos com as outras despesas correntes e de capital.

Interpreta-se que tal fato se deve, em certa medida, ao fraco desempenho econômico do período, uma vez que as contribuições do salário-educação incidem sobre a folha de salários das empresas. De outra parte, em virtude do processo de aceleração inflacionária, o montante total previsto pela Secretaria da Educação para os repasses do salário-educação ficava sistematicamente aquém do valor efetivamente arrecadado pelo INSS. Tais diferenças, de acordo com o texto da lei, deveriam ser corrigidas no início do exercício seguinte. Tais prazos legais, porém, nem sempre foram respeitados.

O "Balanço Geral do Estado" traz também informações dos gastos realizados pelo governo com a função educação e cultura, em que são reunidos os esforços de todos os órgãos do estado comprometidos com os objetivos da prestação daquele serviço público.

No caso da função educação e cultura são somados os gastos realizados pela Secretaria da Educação, Secretaria da Cultura, Secretaria dos Esportes e Turismo e pela Secretaria da Ciência e Tecnologia com as universidades estaduais paulistas (USP, Unicamp e Unesp). O gráfico $\mathrm{V}$ apresenta as despesas realizadas com os três níveis de ensino, em termos reais, ao longo do período de análise.

No gráfico $\mathrm{V}$, quando se confrontam as despesas realizadas com os três níveis de ensino, observa-se um crescimento relativo dos gastos realizados com o Ensino Superior em relação aos gastos realizados com Ensino Fundamental e Médio.

Outro aspecto digno de nota é que o comportamento das despesas com o Ensino Fundamental apresenta grande similitude com as despesas realizadas pela Secretaria da Educação do Estado de São Paulo. E não seria para menos. Do total das despesas da Seesp, cerca de $88 \%$ em média são alocadas no Ensino Fundamental. Afora isso, a participação relativa das despesas com o Ensino Fundamental em relação ao total das despesas da Secretaria da Educação apresenta grande estabilidade no decorrer dos anos analisados. 


\section{Gráfico V}

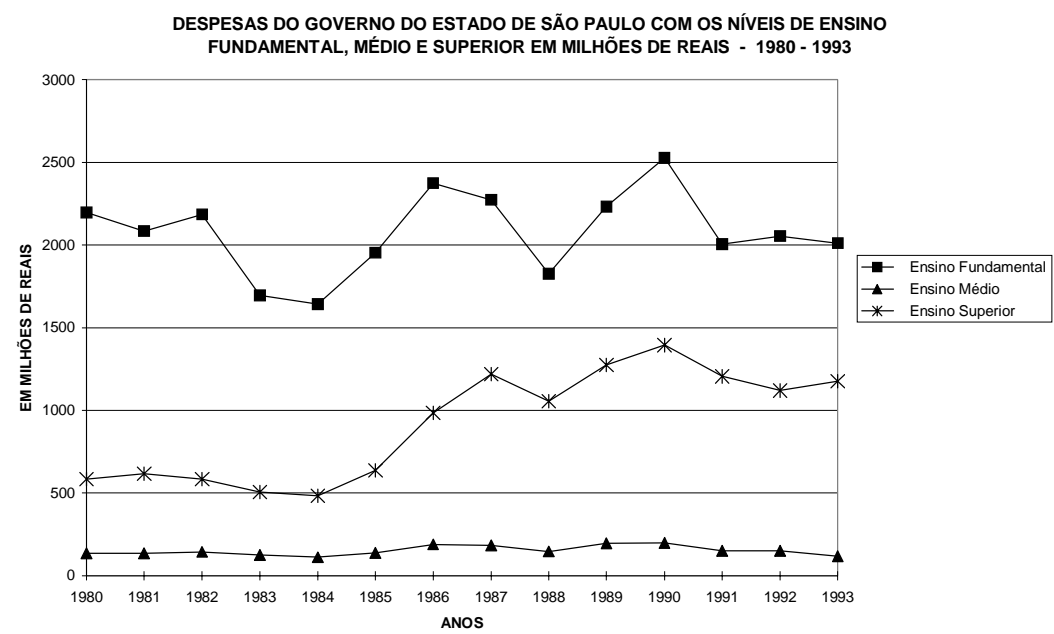

Fonte: Balanços Orçamentários do Estado de São Paulo (1980-1993).

Valores expressos em reais de julho/agosto de 1994, a partir da taxa média de inflação medida pelo IGP-DI.

Em termos reais, entretanto, os recursos alocados no Ensino Fundamental ficaram quase que estagnados. Em média, foram gastos 2,08 bilhões de reais entre os anos de 1980-93, média um pouco inferior à dos primeiros três anos da análise $(2,16$ bilhões de reais) e um pouco superior à do primeiro triênio da década de 1990 (2,02 biIhões de reais). Alternativamente, ao dividir o período de análise em dois subperíodos, verifica-se que o volume médio de recursos empenhados no Ensino Fundamental foi de 2,02 bilhões de reais nos anos de 1980 a 1986 e de 2,13 bilhões de reais para os anos seguintes, de 1987 a 1993.

A gestão do subprograma de Ensino Médio também fica a cargo da Secretaria da Educação. A participação desse nível de ensino nas despesas totais da Seesp manteve-se relativamente constante, em torno de $6,4 \%$ em média ao longo do período de análise. Dessa forma, o comportamento das despesas realizadas é muito semelhante ao observado para o Ensino Fundamental, ou seja, ao longo dos 13 
anos analisados não ocorreu uma alteração significativa em termos reais dos recursos destinados ao financiamento dos gastos com o Ensino Médio.

Em síntese, de tudo o que foi visto, importa salientar que, 13 anos passados do início dos anos 80, o volume de recursos, em termos reais, destinados ao Ensino Fundamental não evoluiu positivamente. Como foi estudado, há evidências de que o fraco desempenho econômico no período e seus reflexos sobre as receitas tributárias (impostos e contribuições sociais) tenham condicionado, em grande parte, a estagnação dos recursos efetivamente alocados no Ensino Fundamental.

É importante reiterar que, ao longo dos anos de 1980 a 1993, as despesas totais do estado de São Paulo aumentaram vigorosamente. Para fazer frente a esse volume crescente de gastos, diante do fraco desempenho das receitas tributárias no período, o governo estadual passa a incorrer em déficits e a contratar dívidas cada vez mais vultosas. Entretanto, se muitos itens da despesa do estado cresceram nesse período, a despeito da conjuntura recessiva, o mesmo não ocorreu com a manutenção e o desenvolvimento do Ensino Fundamental, que perdeu importância frente a outros itens da despesa do estado.

\section{Alguns indicadores sociais de educação}

Com base nos dados apresentados, a questão que se coloca é saber qual o impacto do padrão de financiamento observado nesse período sobre a evolução do sistema público de Ensino Fundamental atendido pelo governo do estado de São Paulo.

Para tanto, deve-se agregar as informações contidas em alguns indicadores sociais de educação que permitirão que se verifique quais os contornos da rede estadual de Ensino Fundamental e suas mudanças qualitativas e quantitativas mais relevantes no período estudado. Para a coleta desses indicadores sociais foram utilizados dados consolidados pela Assessoria Técnica de Planejamento e Controle Educacional da Seesp e dados primários obtidos no Anuário Estatístico de Educação do Estado de São Paulo. 
Uma análise desses dados evidencia que o nível de Ensino Fundamental sofreu, entre 1980 e 1993, grande expansão. Nesse período, o número de matriculados na rede pública estadual de Ensino Fundamental cresceu pouco mais de $50 \%$. Como parcela importante das outras despesas correntes e de capital da Seesp foi empenhada na rubrica investimentos, o Estado pôde ampliar vigorosamente o número de estabelecimentos de ensino. Da mesma maneira, também cresceu o número de professores contratados. A avaliação que se faz é que para o estado de São Paulo, tomado como universo de análise, pode-se dizer que a expansão do número de matrículas foi acompanhada de expansão proporcional dos recursos físicos e humanos.

A tabela 1 sintetiza esses resultados, apresentando as taxas de crescimento do número de matrículas, escolas, classes e docentes do Ensino Fundamental da rede pública estadual paulista. Como só se dispõe de dados para o número de estabelecimentos de ensino a partir de 1982 e dados para o número de docentes a partir de 1985, construíramse duas taxas de crescimento: uma que abrange os anos de 1985 até 1992 e outra para o período de 1982 até 1992 (que exclui, então, os dados para o crescimento do número de docentes).

\section{Tabela 1}

TAXAS DE CRESCIMENTO DO NÚMERO DE MATRÍCULAS,

ESCOLAS, CLASSES E DOCENTES DO ENSINO FUNDAMENTAL DA REDE

PÚBLICA ESTADUAL PAULISTA - 1985-1992 E 1982-1992

\begin{tabular}{|l|c|c|c|c|}
\hline & MATRíCULAS & ESCOLAS & CLASSES & DOCENTES \\
\hline Taxa crescimento 85-92 & 28,9 & 26,7 & 28,4 & 37,1 \\
\hline Taxa crescimento 82-92 & 40,4 & 41,4 & 45,0 & - \\
\hline
\end{tabular}

Fonte: A partir de dados do Anuário Estatístico de Educação do Estado de São Paulo e da Secretaria da Educação/SP - Assessoria Técnica de Planejamento e Controle Educacional - Centro de Informações Educacionais (ETIE).

Pode-se notar que para os anos de 1985 a 1992 as matrículas iniciais, o número de escolas e de classes de Ensino Fundamental crescem 
proporcionalmente. O crescimento do número de docentes desse nível de ensino é mais elevado, o que à primeira vista poderia indicar até uma melhoria nos padrões de atendimento do ensino.

Novamente, para um período de tempo um pouco mais amplo, de 1982 até 1992, verifica-se que as taxas de crescimento das matrículas, escolas e classes crescem no mesmo compasso. Portanto, ao que tudo indica a expansão do número de matrículas foi acompanhada por uma expansão proporcional dos recursos físicos e humanos, quando se toma como universo de análise o estado de São Paulo.

Ora, sendo a rede de Ensino Fundamental ampliada sem que fossem aumentados os recursos destinados à gestão desse sistema, seriam previsíveis conseqüências desastrosas para a qualidade do ensino praticado. Isso só não teria ocorrido se existissem indicações de que nesse período houvera políticas orientadas no sentido do uso mais eficiente dos recursos, ou que, por outra, os recursos disponíveis tivessem sido redirecionados para elementos que pudessem contribuir para um aumento da qualidade do sistema de ensino. Contudo, não há indicação de que qualquer uma das duas possibilidades tenha efetivamente sucedido.

Além do mais, uma tal situação é tanto mais grave quando se compreende que naquele momento ocorriam intensas transformações técnico-científicas que demandariam um volume ainda maior de recursos investidos em elementos físicos e humanos. ${ }^{16}$

No entanto, alguns indicadores apontavam a precariedade de muitas das escolas da rede pública estadual no que se refere à infraestrutura e às condições de ensino. ${ }^{17}$ Além da grande freqüência de problemas na manutenção de prédios, instalações e mobiliários, a maior parte das escolas não dispunha de bibliotecas, laboratórios ou equipamentos para a prática da educação física.

No que diz respeito aos recursos humanos, o comportamento dos salários reais percebidos pelo pessoal docente é um importante indicador da qualidade do sistema de ensino. É impressionante constatar que, ao longo dos 13 anos analisados, o salário auferido pelos professores da rede de ensino estadual sofreu uma perda de quase $80 \%$ em seu valor real, como pode ser observado no gráfico VI que apresenta a variação do salário real dos professores de nível PI (ou PIII) e, para efeito de comparação, a evolução do salário mínimo nos anos de 1980 a $1993 .^{18}$ 


\section{Gáfico VI}

ÍNDICES DE SALÁRIO ANUAL DOS DOCENTES DA REDE PÚBLICA DE ENSINO DO ESTADO DE SÃO PAULO E DO SALÁRIO MÍNIMO - 1980 - 1993

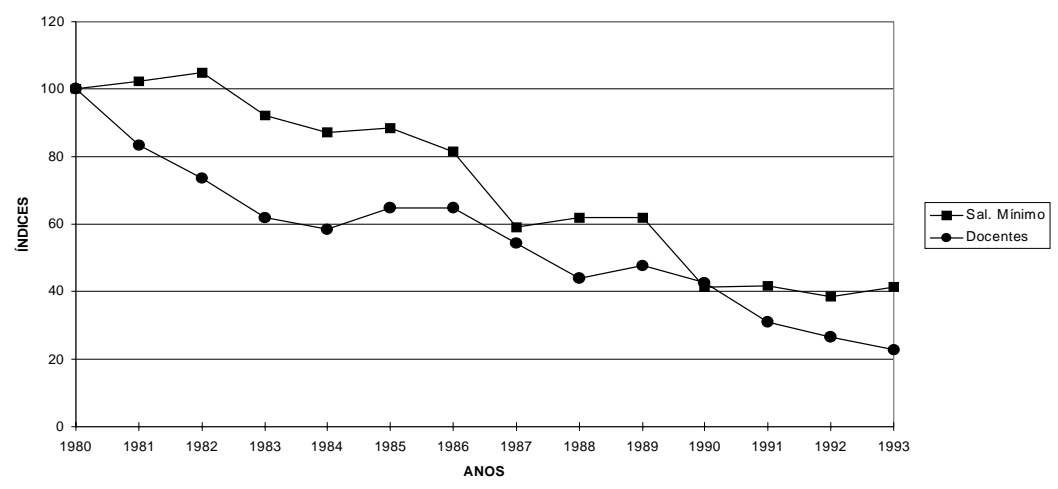

Fonte: Cedi 1993.

Notas: Índice de salário real dos professores e do salário mínimo calculado a partir da massa anual de salários. Para os professores foram considerados os pisos mensais de salários das categorias PI e PIII para uma jornada semanal de 20 horas de trabalho. Taxa de inflação medida pelo Dieese.

Como foi visto, ao longo dos anos de 1980 a 1993, os recursos destinados ao Ensino Fundamental, em termos reais, permaneceram praticamente estagnados. Nesse período, com grande estabilidade, em média $77 \%$ das despesas totais da Secretaria da Educação do Estado de São Paulo foram consumidas com o item pessoal e reflexos. Porém, o número de professores da rede pública estadual de ensino, apenas para os anos de 1985 a 1992, para os quais se dispõe de dados, cresceu vigorosamente. Conclui-se, assim, que o resultado não poderia ser diferente do verificado.

Submetidos a tal perda salarial, não é difícil imaginar que os professores se sentissem desmotivados para o exercício do magistério. Além do mais, recebendo salários tão baixos os professores tinham de recorrer ao expediente de ampliar suas horas de trabalho. É evidente que desse processo só poderia resultar uma piora na qualidade do ensino ministrado em virtude do esgotamento físico e mental dos professores que, 
ademais, não dispõem de tempo para se atualizar ou se dedicar à adequada preparação das aulas.

Outro efeito perverso dessa política de compressão salarial é conhecido na literatura econômica como "seleção adversa". O rebaixamento dos salários dos professores acaba por afastar os melhores profissionais da rede de ensino pública, os quais passam a procurar outras colocações mais rentáveis em escolas da rede particular ou mesmo em outros tipos de ocupação.

Ainda em relação à situação do magistério, o grande número de professores Admitidos em Caráter Temporário (ACTs) é outro indicador a atestar a baixa qualidade do sistema de ensino de competência do governo estadual. O problema é que os professores não concursados, diante da necessidade de ensinar em várias escolas, não podem se envolver no desenvolvimento de projetos pedagógicos para a melhoria do ensino. Além disso, a falta de vínculos mais estreitos desses docentes com a comunidade a que servem também acarreta prejuízos para a qualidade do ensino praticado.

Para a avaliação da qualidade do sistema de ensino é importante também observar indicadores de evasão e repetência. Estudos realizados demonstram que as estatísticas do Ministério da Educação e Cultura (MEC) equivocavam-se ao apontar que as altas taxas de evasão escolar no Ensino Fundamental eram o principal problema a ser enfrentado pelas escolas. Afora isso, quando a partir dos indicadores oficiais do MEC se simulava a progressão do fluxo de alunos ao longo das classes de ensino, inferia-se que o problema do acesso não estava equacionado. A partir de dados das Pesquisas Nacionais por Amostra Domiciliar (Pnads) comprovou-se o erro das estatísticas do MEC ao demonstrar que, na realidade, as taxas de repetência e não as de evasão é que são muito elevadas. ${ }^{19}$

De outra parte, ficou provado também que o problema do acesso à escola é restrito a algumas regiões miseráveis, especialmente do nordeste rural. Para o estado de São Paulo, sobretudo, não se pode mais falar de falta de escolas, ${ }^{20}$ o que implica a necessidade de uma profunda revisão da política que orienta parcela importante dos recursos para o financiamento da educação para as construções escolares.

Práticas como as da "repetência branca" e da "subseriação" estariam na raiz das diferenças constatadas entre os resultados das estatísticas oficiais e os obtidos por Ribeiro (1992) por meio das Pnads. ${ }^{21}$ Acredita-se que as altas taxas de repetência são, em maior medida, reflexo 
de problemas internos ao próprio sistema de ensino do que derivam da situação de miséria dos próprios alunos.

Nesse sentido, argumenta-se que a grande expansão do sistema de ensino público, sobretudo a partir dos anos 70 , com a incorporação de grandes contingentes de alunos provenientes de famílias de baixa renda não foi acompanhada por modificações da estrutura escolar para a adaptação a essa nova clientela. ${ }^{22}$

Atesta-se assim, de maneira inequívoca, a baixa eficiência do sistema de ensino que não oferece a seus alunos a possibilidade de progredir em seus estudos. Apesar desse quadro, as famílias fazem enorme esforço para educar seus filhos, sendo que as crianças permanecem na escola, em média, tempo mais do que suficiente para, teoricamente, completar a escolaridade básica. Entretanto, os sucessivos fracassos que irão recolher em sua vida escolar acabam por fazer com que muitas desistam dos estudos mesmo antes de terem terminado os oito anos de escolaridade obrigatória. ${ }^{23}$

Outras pesquisas apontam para deficiências dos sistemas de ensino no Brasil que não foram desenvolvidas neste trabalho. Argumentase que os sistemas educacionais são extremamente centralizados e verticalizados, com o que se tornam pouco eficientes o acompanhamento, o controle e a correção das políticas orientadas a partir das Secretarias de Educação. Como conseqüência da extensão dos corpos burocráticos, grande parcela dos recursos é consumida nas atividades-meio (funções administrativas) quando poderia ser redirecionada à melhoria do ensino nas escolas. ${ }^{24}$

Nesse sentido, é importante ressaltar que os recursos necessários para promover a formação continuada dos professores da rede de ensino e para cuidar da manutenção das escolas e equipá-las com equipamentos audiovisuais, laboratórios e bibliotecas representam pequena parcela do que é gasto com a construção de uma unidade escolar. ${ }^{25} \mathrm{Se}$, como foi verificado, o problema do acesso ao ensino parece ter sido quase equacionado, recursos empenhados nas despesas de investimentos poderiam ser redirecionados para a concretização de algumas dessas ações que podem contribuir para o aumento da eficiência dos sistemas escolares.

Entretanto, apenas a reorientação dos recursos destinados à educação é claramente insuficiente. A definição clara de uma política pública no campo educacional que possa contribuir para o desenvolvimento do país não pode prescindir da ampliação significativa do aporte de re- 
cursos para a educação. Pois, mesmo que se considere que algumas práticas de baixo custo podem ser implementadas com vistas à melhoria da qualidade do ensino ministrado, a valorização da profissão do magistério e a recomposição dos salários dos docentes exigem um volume de recursos muito superior ao que tem sido destinado ao setor educacional.

\section{Notas}

1. A esse respeito ver o artigo de Silva (1978). Em interessante argumentação o autor afirma que na questão da diminuição das desigualdades sociais a presença do Estado como planejador se faz imperativa, uma vez que o perfil dos investimentos que hoje se realizam determina a distribuição de renda futura.

2. A esse respeito ver o artigo de Mello (1991).

3. São muitos os autores partidários dessas idéias. Entre eles pode-se destacar Carvalho (1993), Cepal (1990), Ferretti et al. (1994), Mello (1991) e Salm e Fogaça (1992).

4. O governo do estado de São Paulo, por intermédio de sua Secretaria de Educação, era responsável, em 1980, por $80 \%$ das matrículas iniciais no Ensino Fundamental no estado. Nesse mesmo ano, os municípios respondiam por $10,5 \%$ e as escolas particulares, $9,5 \%$ das matrículas nesse nível de ensino. Em 1994, as escolas estaduais ainda eram responsáveis por $78,7 \%$ do total das matrículas, enquanto aos municípios e às escolas particulares cabiam, respectivamente, 9,5\% e $11,8 \%$ das matrículas iniciais no Ensino Fundamental. A fonte privilegiada para a coleta desses dados é a publicação Sinopses Históricas do MEC/Sediae/Seec.

5. Para uma avaliação das características principais das políticas educacionais articuladas pelo regime militar que subiu ao poder em 1964, uma referência é o artigo de Mello e Silva (1992).

6. A Lei $n^{\circ} 7.348$ de 24/7/1985 veio a regulamentar a Emenda Calmon, esclarecendo alguns pontos que haviam sido objeto de controvérsias. Entre outros aspectos, a Lei $n^{\circ} 7.348$ objetivava discriminar as despesas que seriam consideradas como de manutenção e desenvolvimento do ensino.

7. Para uma discussão pormenorizada dos impactos da Constituição de 1988 e dos termos do federalismo fiscal no Brasil, ver Afonso (1994).

8. Um estudo bastante completo do salário-educação pode ser encontrado em Cyrillo et al. (1993).

9. Em relação à Quota Federal do Salário-Educação (QFSE), uma das formas de transferências federais, Cyrillo et al. (1993) demonstram que, no período de 
1982 a 1988, o estado de São Paulo recolheu, em média, 44,2\% do total dos recursos do salário-educação, porém, só recebeu, em média, 1,8\% dos recursos distribuídos a título da QFSE.

10. Para uma descrição pormenorizada das principais fontes de receita da Secretaria de Educação para o período em estudo, ver Tuma (1985).

11. As despesas com o ensino público estadual de nível superior não são de competência da Secretaria de Educação do estado de São Paulo e incluemse nas despesas da Secretaria da Ciência e Tecnologia.

12. Não existem outras fontes primárias para o estudo do financiamento das contas do estado. Por vezes, o Ministério da Fazenda realiza um esforço de compilar as execuções orçamentárias dos estados e de suas capitais, porém, essas publicações apresentam os dados de forma excessivamente agregada.

13. É importante ressaltar que para os objetivos desta análise são utilizados dados do resultado do balanço orçamentário do Estado e não dados do orçamento. O orçamento do Estado deveria ser uma peça de grande importância para o planejamento, execução e controle das ações praticadas pelo governo. Porém, em virtude do processo de aceleração inflacionária, sobretudo a partir do final dos anos 70, as despesas efetivamente realizadas pelos diversos órgãos do estado superavam sistematicamente as previsões orçamentárias.

14. Convém notar que os dados de impostos apresentados não são os dos impostos líquidos das transferências. A rigor, é sobre estes últimos que deve incidir a alíquota de $25 \%$ para manutenção e desenvolvimento do ensino. De qualquer forma, como os percentuais de transferência são fixados na Constituição, ambos os elementos de receitas seguem trajetórias perfeitamente paralelas.

15. A esse respeito ver também Fipe (1995). Nesse relatório existe a avaliação de que "renúncias fiscais, corrupção e desorganização administrativa" também contribuíram para os resultados insatisfatórios das receitas tributárias.

16. A esse respeito ver Tedesco (1991).

17. Com base em levantamento realizado pela Apeoesp em 1990, em escolas distribuídas pelas 17 divisões regionais de ensino, na região metropolitana e interior. A esse respeito ver Cedi (1993).

18. O índice de salário real dos professores e do salário mínimo foi calculado com base na massa anual de salários. Tal procedimento consistiu em considerarse o piso de salário das categorias PI e PIII para uma jornada semanal de 20 horas e o salário mínimo vigente. A cada mês deflacionou-se o salário nominal correspondente pela taxa de inflação medida pelo Dieese. Os salários reais de um ano foram então somados e a seguir escolheu-se 1980 como ano-base.

19. O erro das estatísticas oficiais do MEC foi comprovado por Ribeiro (1992), que se utilizou de um modelo matemático, o Profluxo, alimentado pelos dados da Pnads (Pesquisa Nacional por Amostra de Domicílio), do IBGE. 
20. Em algumas localidades é provável que persista a falta de vagas nas escolas ou mesmo de estabelecimentos de ensino. Ocorre que, ao longo dos últimos anos, muitas escolas surgiram sem o acompanhamento de um estudo demográfico sério que contemplasse a distribuição espacial da clientela escolar. Além do mais, deve-se considerar que nas grandes metrópoles o rápido movimento de urbanização e a concentração de grandes contingentes populacionais nas periferias das grandes cidades acarretaram dificuldades no ajuste das ofertas de vagas escolares que levassem em conta a localização do alunado.

21. A prática da "repetência branca" consiste em aconselhar os alunos com dificuldades em acompanhar o andamento dos conteúdos escolares a desistirem antes das avaliações finais. A "subseriação" representa a subdivisão informal de uma determinada série, de forma que o aluno reprovado é considerado "promovido" para uma outra subsérie da mesma série escolar. Tanto num caso como no outro, como o aluno não é oficialmente reprovado, ele engrossa a fileira dos evadidos e, ao matricular-se no ano seguinte, na mesma série, aparece nas estatísticas oficiais como um novo aluno.

22. O trabalho de Collares (1994) demonstra que professores e profissionais de saúde tendem a atribuir a deficiências das próprias crianças ou de suas famílias as causas do fracasso escolar, sendo que o próprio sistema escolar é isentado de responsabilidade.

23. É importante notar que mesmo os evadidos permanecem em média 6,4 anos na escola, o que atesta a disposição das famílias e dos alunos em adquirir uma educação formal mesmo após a experiência de numerosos fracassos. Conforme Ribeiro (1992).

24. A esse respeito ver artigo de Mello (1991).

25. Com base em boletim divulgado pela própria Seesp, quando da criação das escolas-padrão, verifica-se que os montantes destinados à construção das unidades escolares eram de ordem muito superior ao dos recursos que seriam consumidos nos cursos de retreinamento dos docentes e na compra de equipamentos que propiciassem melhores condições de ensino (como, por exemplo, microcomputadores, acervo de livros, laboratórios, e equipamentos de televisão e vídeo). De outra parte, o estudo de Castro (1982) comprova que os gastos com os recursos pedagógicos não representam mais do que uma parcela ínfima dos custos totais implicados na construção das unidades escolares.

\section{The management of the primary teaching by the S.P. state: An analysis of the loan and of the social indicators of education}

ABSTRACT: This work contributes with the evaluation of the public primary education system administered by SEESP, the office that is responsible for public policies on education in the state of São Paulo (Brazil) between the years of 1980 and 1993. In order to do so, an empirical study of the finances of the state 
of São Paulo was executed and some social indicators of education were added to this analysis. We show that the amount of resources destined to the primary level have not changed in a significant way during this period, although the enrolments have increased, as well as, proportionally, the physical and human resources. As a result of this process the teachers have experienced a huge loss in their purchasing power. On the evidence of high repetition rates, authoritarian pedagogical practices, lack of motivation of the teachers and deficient physical resources, we testify the inefficiency of the educational system.

\section{Bibliografia}

AFONSO, J.R. Descentralização fiscal na América Latina: Estudo de caso do Brasil. Santiago do Chile: Cepal, 1994. (Série Política Fiscal, $\mathrm{n}^{\circ} 61$ )

CONSTITUIÇÃO DA REPÚBLICA FEDERATIVA DO BRASIL. São Paulo: Imprensa Oficial do Estado, 1988.

CARVALHO, R.Q. "Projeto de Primeiro Mundo com conhecimento e trabalho de Terceiro?" Estudos Avançados n 17, v. 7. São Paulo, jan./ abr. 1993, pp. 35-78.

CASTRO, C.M. "Onde está o desastre?" Em Aberto nº 44, ano VIII. Brasília, out./dez. 1985, pp. 31-33.

CEDI. Apeoesp dez anos - 1978/1988: Memória do movimento dos professores do ensino público estadual paulista. São Paulo: Cedi (Centro de Documentação e Informação), 1993.

CEPAL. Transformación productiva con equidad. Santiago do Chile: Cepal, 1990.

COLLARES, C.A.L. "O cotidiano escolar patologizado". Tese de livredocência. Campinas: Faculdade de Educação da Unicamp, 1994.

CYRILLO, D.C.; GONÇALVES, P.J.; FONSECA, E.G. "Arrecadação e distribuição do salário-educação em São Paulo". São Paulo: IPE/ USP-SEE/SP, 1993.

FERRETTI, C.J. et al. (org.). Novas tecnologias, trabalho e educação: Um debate multidisciplinar. Petrópolis: Vozes, 1994. 
FIPE. Análise dos fatores responsáveis pelo declínio da economia paulista e as perspectivas das regiões administrativas do estado de São Paulo. São Paulo: Fipe/USP, maio 1995.

FRACALANZA, P.S. "O financiamento da educação: A ação do governo do estado de São Paulo (1980-1993)". Dissertação de mestrado. São Paulo: Faculdade de Economia, Administração e Ciências Contábeis da USP, 1995.

MELLO, G.N. "Políticas públicas de educação". Estudos Avançados nº 13, v. 5. São Paulo, set./dez. 1991, pp. 7-47.

MELLO, G.N. e SILVA, R.N. da. "O que pensar da atual política educacional?" Em Aberto no 50/51. Brasília, abr./set. 1992, pp. 3-17.

RIBEIRO, S.C. "A pedagogia da repetência". Estudos Avançados nำ12, v. 5. São Paulo, maio/ago. 1991, pp. 7-21.

SALM, C. e FOGAÇA, A. "Modernização industrial e a questão dos recursos humanos". Economia e Sociedade ํㅜㅅ. Campinas, ago. 1992, pp.89-109.

SILVA, A.M. Distribuição de renda e senso comum. São Paulo: IPE/USP, 1978. (Coleção Ensaios Econômicos, nº 10)

TEDESCO, J.C. "Estrategias de desarrollo y educación: El desafío de la gestion pública". Pensamiento Iberoamericano nº 19, 1991.

TUMA, F.M.M. "Financiamento da Secretaria de Estado da Educação de São Paulo: Sistema de macrogerenciamento Prodesp/SE". Relatório de pesquisa. Campinas, Convênio Unicamp/Fundap/Nepp, 1985. 